\title{
Os Pentecostais, o Espírito Santo e a Reforma
}

\author{
Pentecostals, Holy Spirit and Reformation \\ Los pentecostales, el Espíritu Santo y la Reforma
}

\section{David Mesquiati de Oliveira*}

Faculdade Unida de Vitória (UNIDA), Vitória, ES, Brasil

\section{Resumo}

Os pentecostais estão separados historicamente da Reforma do século XVI, porém, também se sentem herdeiros desta tradição. Contudo, sua visão sobre o Espírito Santo é peculiar. Na esteira dos pilares da Reforma Protestante o pentecostalismo apresentaria um quinto elemento, que chamamos aqui de Solus Spiritus Sanctus. $\mathrm{O}$ texto está dividido em três seções. Na primeira reflete sobre a mística e sobre o humanismo pentecostal, que são diferentes da mística e do humanismo da época da Reforma. Na segunda busca-se mapear brevemente a pneumatologia pentecostal para, na terceira seção, analisar a contribuição pentecostal para a Ecclesia reformata et semper reformanda est.

Palavras-chave: Pentecostalismo. Reforma. Espírito Santo.

DM0: Doutor em Teologia, e-mail: david@faculdadeunida.com.br 


\section{Abstract}

The Pentecostals are historically separated from the Reformation of the sixteenth century, but also feel heirs to this tradition. However, his view of the Holy Spirit is specific. In the wake of the pillars of the Protestant Reformation, Pentecostalism would present a fifth element, which we call here Solus Spiritus Sanctus. The text is divided into three sections. In the first it reflects on mysticism and Pentecostal humanism, which are different from the mysticism and humanism of the Reformation era. In the second section, the Pentecostal pneumatology will be briefly mapped so that, in the third section, the Pentecostal contribution to Ecclesia reformata et semper reformanda est.

Keywords: Pentecostalism. Reformation. Holy Spirit.

\section{Resumen}

Los pentecostales están separados históricamente de la Reforma del siglo XVI, pero también se sienten herederos de esta tradición. Sin embargo, su visión sobre el Espíritu Santo es peculiar. En la estera de los pilares de la Reforma Protestante el pentecostalismo presentaría un quinto elemento, que llamamos aquí de Solus Spiritus Sanctus. El texto está dividido en tres secciones. En la primera reflete sobre la mística y sobre el humanismo pentecostal, que son distintos de la mística y del humanismo de la época de la Reforma. En la segunda se busca mapear brevemente la pneumatologia pentecostal para, en la tercera sección, analizar la contribución pentecostal para la Ecclesia reformata et semper seformanda est.

Palabras-clave: Pentecostalismo. Reforma. Espíritu Santo.

\section{Introdução}

Os pentecostais formaram um numeroso grupo de pessoas religiosas no mundo com crenças intensas e efusivas, que geraram uma nova classificação nos estudos de religião: pentecostalismo. O termo 
característico vem da festa judaica Pentecostes, ocasião que, segundo o Novo Testamento, teria sido derramado o Espírito Santo sobre os seguidores de Jesus na nascente igreja cristã. Dessa experiência extática se seguiram várias outras nas igrejas dos começos, com relatos de curas, êxtases, milagres, entre outros (DAYTON, 1991). Dando um salto na história e chegando ao final do século XIX e início do XX, pequenos grupos cristãos oriundos dos avivamentos ingleses e estadunidenses (revivals) buscaram reproduzir a experiência do Novo Testamento no modelo do relatado nos dias de Pentecostes. Aquela forma de atuação do divino e as experiências concretas das primeiras comunidades começaram a ser reproduzidas novamente. A alegação é que o Pentecostes não era somente um evento histórico e restrito ao passado, mas, ao contrário, seria normativo para a igreja, isto é, deveria dar-se novamente em cada geração. Com isso, os dons atribuídos ao Espírito Santo e os efeitos desse agir estariam em plena continuidade com as páginas do Novo Testamento. Por conta dessa ênfase no modelo do Pentecostes esses grupos ficaram conhecidos como pentecostais (CAMPOS, 2002). De forma pejorativa, também o chamavam de pentecostistas, mas tal uso não preponderou na academia.

Por volta da segunda metade do século XX, a pentecostalização das igrejas brasileiras amplia seu alcance, não sem alterações em sua forma e conteúdo (FRESTON, 1993). Nessa nova fase, a ênfase está nos dons (carismas), e chega como uma forma de renovação das igrejas, sem romper com os demais elementos constitutivos. Assim, aparecem as chamadas igrejas renovadas ou da renovação carismática, o que inclui protestantes e católicos. Além da Renovação Carismática Católica (RCC) na década de 1960, há também igrejas batistas renovadas, presbiterianas renovadas, metodista renovada (wesleyana). É nesse período que surgem também outras igrejas pentecostais como a Igreja do Evangelho Quadrangular, a Igreja Pentecostal o Brasil para Cristo e a Igreja Pentecostal Deus é Amor.

Por último, na década de 70 e 80, algumas igrejas adotaram uma postura mais agressiva no grande mercado religioso brasileiro, sob forte cooptação econômica. Nesses grupos o foco recaiu no resultado da fé para a vida concreta, estimulando uma religiosidade de trocas baseada da utilidade da religião. Expoentes dessa nova opção de ser cristão no Brasil e depois em várias regiões do mundo foram a Igreja Cristã Nova 
Vida (liderada pelo Bispo Robert McAlister), de onde saíram a Igreja Universal do Reino de Deus (do Bispo Edir Macedo), a Igreja Internacional da Graça de Deus (do Missionário R. R. Soares) e Ministério Cristo Vive (do Apóstolo Miguel Ângelo). Juntar-se-ia ao grupo a Igreja Mundial do Poder de Deus (do Apóstolo Valdemiro Santiago) e a Igreja Renascer (do Apóstolo Estevão Hernandes e da Bispa Sônia), e ultimamente, a Igreja Apostólica Plenitude do Trono de Deus (do Apóstolo Agenor Duque). A literatura os denominou de "neopentecostais" (MARIANO, 1999), uma vez que parte dessas igrejas eram uma variação das igrejas pentecostais, como o fundador da influente Igreja Cristã Nova Vida, que antes se chamava Igreja Pentecostal de Nova Vida, Robert McAlister, oriundo das Assembleias de Deus do Canadá, e veio ao Brasil na década de 60 a convite das Assembleias de Deus brasileiras e da Igreja do Evangelho Quadrangular.

Mas a base dessas igrejas, a chamada teologia da prosperidade, não é uma exclusividade desses novos pentecostais, pois a lógica economicista afetou outros grupos religiosos e equivocadamente é usado por alguns analistas como sinônimo da pentecostalização. Por isso, e para evitar embates taxinômicos que neste texto não são o propósito, vamos nos concentrar nos primeiros grupos pentecostais no Brasil, representado por denominações como as Assembleias de Deus e que na literatura recebem o nome de pentecostalismo clássico (FRESTON, 1994). As Assembleias de Deus no Brasil surgiram a partir da Igreja Batista em Belém do Pará em 1911. Os missionários suecos, Daniel Berg e Gunnar Vingren, mantiveram contato com a Igreja Filadélfia de Estocolmo, de orientação pentecostal e batista, mas que em 1913 foi expulsa da convenção batista sueca. O líder desta igreja, Lewi Pethrus (que a pastoreou de 1911 a 1958), enviou vários missionários que contribuíram muito para o fortalecimento do pentecostalismo brasileiro (ALENCAR, 2013). O grupo dos batistas, por sua vez, tem sua origem histórica nos anabatistas do século XVI e nos puritanos do século XVII. São, portanto, filhos da reforma protestante. Os pentecostais, como "geração posterior", pois advém não só dos batistas, mas também dos metodistas (com origem na Igreja Anglicana), seriam os "irmãos menores", como aparece na sugestiva obra La madurez del hermano menor do teólogo pentecostal peruano Bernardo Campos (2012). 
Temos assim, a relação entre os pentecostais a Reforma, embora estejam separados por quatro séculos. O elemento que daremos mais atenção aqui, será a pneumatologia dos pentecostais, que com sua visão específica do Espírito Santo, confere à Reforma Protestante uma perspectiva própria, que chamaremos neste texto de o Solus Spiritus Sanctus, como referência aos pilares da Reforma Protestante. O texto está dividido em três seções. Na primeira reflete sobre a mística e o humanismo pentecostal, que são diferentes da mística e do humanismo da época da Reforma. Na segunda busca mapear brevemente a pneumatologia pentecostal para, na terceira seção, analisar a contribuição pentecostal para a Ecclesia Reformata et Semper Reformanda est.

\section{Mística pentecostal}

Consideramos dois tipos de misticismo no que diz respeito ao cristianismo, sendo um positivo e outro com efeitos negativos. O que seria positivo chamaremos de misticismo integrador e o negativo, de misticismo segmentador, pois estas seriam suas características principais. Seria integrador o tipo de misticismo que estiver relacionado ao sentido clássico do termo "mística", enquanto contemplação, como uma experiência profunda de proximidade e imersão no divino. Aqui há uma possibilidade de imediato conhecimento interior do divino, considerando que Deus pode agir por meios que desconhecemos, e nesse sentindo, abrindo-se para comunicar-se com ele por outras vias que não unicamente a cognitiva. Essa possibilidade de contato direto e imediato não deveria substituir as outras vias, mas daria intensidade ao que se vive como comunidade e como tradição, podendo, em alguns casos, introduzir novas práticas. No relacionado à teologia não excluiria a questão apofática nem a valorização da experiência pessoal. Trata-se de uma via que reconhece Deus como mistério, mas que também, por iniciativa dele, pode dar-se a conhecer. São valiosas aqui as dimensões da afetividade e do espiritual. No misticismo integrador o divino não seria encontrado na profundidade da alma, como se houvesse identificação entre o ser divino e a essência do humano, mas seria nesse ambiente profundo que encontraria as condições para ouvir e discernir o Espírito. 
O misticismo do tipo segmentador, por sua vez, seria aquele que usaria da sua experiência para afastar-se do grupo e romper os laços com os demais sob pretensa superioridade, seja da ordem do conhecimento de Deus, da sua vontade ou da suposta proximidade com ele. Sua via de acesso é vista como a única forma de conhecimento e acesso ao sagrado. Menospreza os ritos, os sacramentos, os textos sagrados, a tradição, as instituições, a teologia e vê-se como autossuficiente. Aqui, ao invés da mística somar ao cristianismo, ela gera enfrentamentos e divisões. Thomas Merton (2007), por exemplo, já tinha chamado a atenção para o necessário mútuo enriquecimento entre teologia formal e uma espiritualidade sadia.

Na nossa perspectiva, o pentecostalismo moderno surge no século XX com uma proposta mística do tipo integradora. Eram membros de diferentes comunidades em busca de uma experiência com o Espírito. Contudo, a maneira como as lideranças e parte das comunidades avaliaram essas experiências foi negativa, e devemos considerar que as práticas dos primeiros pentecostais não eram sem exageros. Como fruto da modernidade de recorte racionalista e dos traumas na história da igreja com os grupos espiritualistas, a reação era, no mínimo, de desconfiança. O nascimento das Assembleias de Deus no Brasil em 1911 aconteceu depois que cerca de 20 pessoas, sob influências de missionários estrangeiros que traziam o chamado "avivamento do Espírito", buscavam falar em outras línguas e profetizar, emulando as experiências narradas no Novo Testamento. A reação foi enérgica, com a expulsão dessas pessoas do seio da comunidade (igreja batista). Podemos citar os exemplos das igrejas renovadas, que resultaram em divisões das igrejas evangélicas tradicionais em meados do século XX. Mas não podemos ser ingênuos para achar que tais rachas aconteceram simplesmente porque o novo grupo era sedicioso: há disputa de poder em jogo, negação da veracidade da experiência do outro, desprezo por essa via de espiritualidade como fonte genuína, entre outros. Não podemos eximir a responsabilidade dos dirigentes nacionais dessas denominações, nem os excessos dos grupos "renovados". A questão é que, ao evitar-se o misticismo do tipo segmentador, sem perceber, estavam negando também, vida e expressão do misticismo integrador, que poderia contribuir para uma renovação (e até mesmo de uma reforma) da igreja a partir de dentro, da intensidade da fé. 
Tal qual há diferenças entre Lutero, a Reforma do século XVI e a ortodoxia luterana que se sedimentou, há, também, diferença entre o que moveu os pentecostais no início e o que, concretamente, se tornaram os pentecostalismos na América Latina, à medida em que foram se sedimentando na região. No tempo de Lutero se queria evitar a suficiência das obras para a salvação (ALTMANN, 1994), mas esta sua ênfase acabou desembocando em uma supressão da experiência interior com o Espírito, relegando a uma experiência de segundo plano (GEORGE, 1994). Assim, houve uma passagem do Lutero místico para o Lutero que se fecha a estas experiências. Parte disso se deve a sua perspectiva bíblica de ênfase paulina e à sua hermenêutica. Os pentecostais, ao contrário, não assumiram a perspectiva paulina, mas, sobretudo, a perspectiva lucana, e deram vida às narrativas das igrejas dos começos, transformando o Pentecostes em princípio normativo para a igreja, isto é, em qualquer tempo (DAYTON, 1991). Mesmo a leitura de Paulo (FEE, 1997) e de seus escritos é feita pela ótica da narrativa e da experiência, concentrando-se em textos em que há uma abertura para a ação direta do Espírito sobre o crente, sem mediação externa. A isso estamos chamando aqui de misticismo pentecostal, e a nosso ver pode ser do tipo integrador. Caracteriza-se pelo fervor religioso (expresso na alta frequência ao templo, nas orações espontâneas e na disciplina para uma leitura bíblica sequenciada e de toda Bíblia) e pela relação com Deus por meio do Espírito, com o mínimo de mediação (podendo relativizar os sacramentos e as "expressões externas").

O outro componente chamamos de humanismo pentecostal. Recordando Lutero, é nos dito que ele não negava a ação do Espírito, mas sim a atitude de alguns coetâneos de atribuir à Escritura uma importância relativamente secundária (DELUMEAU, 1977). Sua insistência e originalidade em fazer valer o retorno ao evangelho como um instrumento de uma palingenesia (eterno retorno) religiosa foi em sua época uma força de destruição e renovação (SANTIDRÍAN, 1997). Dessa forma, Lutero uniu-se ao Renascimento em sua busca das origens. O pentecostalismo moderno, na mesma linha, fez sua palingenesia ao Pentecostes e à igreja dos começos, e transformou o Novo Testamento e suas experiências místicas, messiânicas e apocalípticas, em normativas. O humanismo pentecostal ("Ad fontes pentecostal") se caracterizou por 
um retorno ao Novo Testamento, biblicismo (com notas de literalismo) e normatividade do evento e modos operandi do Pentecostes.

\section{A pneumatologia do pentecostalismo clássico}

Considerando a mística pentecostal e seu humanismo peculiar, é de se esperar que sua pneumatologia fosse igualmente sui generis. Donald Dayton (1991) fez uma importante pesquisa sobre as raízes teológicas do pentecostalismo e, encontrou uma relação com o movimento holiness (santidade) metodista norte-americano e com nuances do pietismo europeu. A essência do pentecostal poderia ser descrita a partir da crença no Jesus que salva, cura, batiza com o Espírito Santo e que breve retornará. Esse seria o evangelho pleno, completo. Duas coisas chamam a atenção. A primeira é que essa chave de leitura é cristológica e não pneumatológica, como se esperaria de início. A centralidade está em Jesus: ele salva, aqui e agora e escatologicamente; ele cura as enfermidades e dá esperança de uma vida melhor e digna; ele batiza com o Espírito (importante doutrina pentecostal que explicaremos na sequência), do qual o batizador é Jesus; e por último, a chave apocalítica sobre a expectativa do breve retorno de Cristo, a Segunda Pessoa da Trindade. A maioria dos pentecostais norteamericanos e também dos brasileiros mantiveram esse núcleo-duro. Essa centralidade cristológica apresenta um paráclito (auxiliador) na missão desse Cristo: o Espírito Santo como pessoa e ativamente presente no crente e na igreja. Aqui essa experiência é revestida de uma especificidade que vai além da soteriologia. O Espírito Santo anima, alegra, exorta, consola, distribui dons, convence, entre outros dons (OLIVEIRA, 2016).

A segunda questão é a noção de batismo com o Espírito Santo defendido pelos pentecostais e que não é a mesma noção geral de batismo no Espírito, com o qual todos os crentes seriam imersos na nova vida no Espírito. O batismo pentecostal com o Espírito fala de um revestimento posterior. Não está ligado ao processo de justificação pela fé, mas de uma "segunda bênção" (a primeira foi a salvação) (GILBERTO, 2008). O movimento holiness entre os metodistas defendia que era necessário buscar uma segunda bênção após receber a salvação, que era a santidade pessoal. Essa busca da perfeição cristã teria gerado comunidades propícias 
para experiências místicas e sensitivas. Grupos holiness começaram a experimentar o fenômeno da glossolalia — falar em línguas estranhas - e, nos Estados Unidos, foram os ascendentes diretos e espirituais dos pentecostais modernos, como o caso de Topeka (Kansas) e da Rua Azusa (Los Angeles), berços do pentecostalismo norte-americano. Nesses ambientes metodistas, o batismo com o Espírito Santo era chamado, então, de terceira bênção. No caso brasileiro, seria a "segunda bênção", uma vez que não surgiu em seio metodista como foi nos Estados Unidos.

O batismo pentecostal com o Espírito Santo é defendido como uma doutrina central para o pentecostalismo dito clássico (MENZIES \& MENZIES, 2002). Várias narrativas do Novo Testamento mostram pessoas cristãs (salvas em Cristo) recebendo oração e sendo visitadas de forma especial pelo Espírito, inclusive com manifestação tangível de fenômenos sobrenaturais, como falar em outras línguas, profecia, interpretação de línguas, entre outros. O próprio derramamento do Espírito Santo no Pentecostes aconteceu sobre pessoas crentes. Era já, então, uma segunda bênção para eles. Essa experiência seria estendida e possível a todos os crentes, como em Atos 2.38-39. Em Atos 19.2, Paulo pergunta a um grupo de seguidores de Jesus se eles já tinham recebido o Espírito quando creram, denotando tratar-se de algo tangível e mesmo posterior. Essa expectativa de uma visitação especial do Espírito Santo sobre o crente passa a ser identificada como a promessa pentecostal, um revestimento de poder e comissionamento do Espírito, que segue ao novo nascimento, essencialmente pneumatológica. De fato, essa experiência não tem efeito soteriológico, portanto, não é uma segunda via para a salvação. É antes, uma capacitação especial para o serviço e para a vida cristã consagrada (testemunho cristão).

No âmbito pentecostal o falar em línguas em estado de êxtase passa a ser standard para a espiritualidade cristã que se pratica de forma pessoal nos momentos de orações intensas ou mesmo no culto público. Para se ter uma ideia, não poderia ser apresentado para o ministério pastoral quem não tivesse dado provas à comunidade de ter esses momentos extáticos. Ser batizado com o Espírito Santo é um requisito para a consagração ministerial ao pastorado nas Assembleias de Deus, assim como a formação teológica ou a aprovação na entrevista com o candidato, por exemplo. 
As línguas estranhas são muito importantes para o pentecostal que busca reviver os tempos apostólicos. Esse batismo pentecostal com o Espírito Santo indica que há uma posse e controle do corpo pelo Espírito, começando pela "língua". A língua é sinônimo de "evangelho falado, pregado, cantado, comunicado” (GILBERTO, 2008, p. 183). Esse impulso à proclamação tem sido uma marca no movimento missionário pentecostal, notadamente efusivo e evangelístico. Aqui, a dimensão da corporalidade é importante para entender esse perfil. Afirma Antonio Gilberto (2008, p. 190): "Na conversão, recebemos vida de Deus; no batismo com o Espírito Santo recebemos poder de Deus". Donald Gee (s.d.; 2011), importante teólogo pentecostal inglês e ecumênico do século passado, ressaltava as experiências sobrenaturais que costumam acompanhar o batismo pentecostal. Amos Young (2000), teólogo da Assembleia de Deus dos Estados Unidos, afirma que no pentecostalismo se advoga uma presença ativa do Espírito Santo em todas as áreas da vida, atuando não só por meios externos, mas também internos. Em uma obra recente, o teólogo pentecostal Anthony Palma (2014), teólogo pentecostal norte-americano, atualizou os estudos sobre essa importante doutrina pentecostal.

Outro teólogo assembleiano norte-americano em recente obra, Robert Menzies (2016), destaca que o movimento pentecostal pode oferecer à igreja mundial muito mais que a experiência religiosa e o fervor espiritual: há doutrina e teologia também. Ele destaca, por exemplo, o novo olhar para Lucas-Atos, que não subordina à perspectiva paulina. Nesse sentido é uma ampliação da Reforma ou mesmo elementos para uma nova Reforma. Outro exemplo seria a natureza missiológica do discipulado e da igreja, recordando sua vocação apostólica no poder do Espírito. Por último, as experiências do Espírito Santo na atualidade, sua importância e significância simbólica. Nesse sentido, os sacramentos são ressignificados, pois o falar em línguas passa a ser um "sacramento" dos (e para os) pentecostais.

\section{Os pentecostais e a renovação da Reforma}

Os pentecostais também se veem como herdeiros da Reforma Protestante e no século XX e apareceram como o "irmão menor" em meio à 
família do cristianismo, se quisermos utilizar uma metáfora relativa a uma família com vários irmãos (CAMPOS, 2012). Os mais experientes seriam os “irmãos católicos, ortodoxos e os protestantes". Mas nesse centenário do pentecostalismo moderno é possível falar em amadurecimento do "irmão menor" que, não só aprendeu (e aprende) com seus irmãos mais velhos, mas ao mesmo tempo busca fortalecer sua personalidade e também começa a fazer suas contribuições. A partir dos quatro princípios da reforma (os 4 Sola) e do credo niceno-constantinopolitano do século IV (Creio na igreja una, santa, católica e apostólica) vamos problematizar a perspectiva pentecostal. Esses fundamentos são assumidos pelos pentecostais e conferem identidade cristã e unidade como igreja, mas ao mesmo tempo, os pentecostais recuperam explicitamente a dimensão do Espírito, tornando mais complexa a correlação quaternária tanto dos Sola da Reforma Protestante quanto das marcas da igreja. Aqui, a estrutura é quíntupla.

Na Reforma Protestante ficaram assentados os quatro fundamentos da teologia cristã, que impactou não só a teologia de Lutero e Calvino, mas também na subsequente Reforma católica, levando as discussões para as raízes da teologia. Podemos dizer que esses princípios exclusivos (só Cristo, só a graça, só a fé e só a Escritura) propostos por Lutero ajudaram a recuperar o cerne da teologia cristã. Nesse sentido, os pentecostais assumem esse fundamento teológico da Reforma e sua correlatividade, mas resgatam o protagonismo do Espírito Santo de tal forma que podemos dizer que para os pentecostais há também um Solus Spiritus Sanctus. Esse Espírito Santo não substitui a fé, nem a Palavra, nem a graça nem Cristo, mas atua em correlação. O Solus Spiritus dos pentecostais não poderia ser entendido em sentido escolástico, como se a centralidade no Espírito resultasse em autonomia em relação aos quatro sola ou algum tipo de hierarquia. Não teria muito proveito o Sola Scriptura se o Espírito Santo não a explicasse, nem o Solus Christus se o Espírito não atualizasse e universalizasse sua obra. O mesmo se pode dizer sobre a fé e sobre a graça. O Espírito atravessa inseparavelmente os quatro sola, de tal modo que é justo legitimar sua ação fundante.

O mesmo poderíamos dizer das quatro marcas da igreja cristã, que não é só una, santa, católica e apostólica, mas também, no dizer do teólogo 
pentecostal Bernardo Campos (2002), assume um princípio igualmente fundante para a teologia pentecostal: o princípio da pentecostalidade.

A pentecostalidade não é a pentecostalização da igreja. Tem a ver com assumir a ação do Espírito de maneira ativa na igreja e na teologização, mais do que as formas clássicas de Espírito do Filho ou da força (energia) de Deus. Sua pessoalidade divina é estimada, invocada e presente. A escolha desse termo pelo teólogo pentecostal peruano não tem a ver com os pentecostais de maneira direta, mas com a forma como o Espírito agiu no período do Pentecostes, na igreja dos começos. Essa teologização aberta sobre o Espírito Santo é assumida sem rodeios, sem uma hierarquia dentro da Trindade, como muitas vezes resultam algumas abordagens trinitárias. O princípio pentecostalidade "é a força do Espírito que outorga poder ao ser humano para superar os condicionamentos que querem reduzi-los à desumanização". Mais adiante ele afirma: "quer opor 'espírito' ali onde o ser humano só quer pôr matéria (phisis) e corporeidade ali onde o ser humano quer espiritualizar-se" (CAMPOS, 2002, p. 88).

Recentemente, Bernardo Campos (2016) consolidou essa perspectiva em uma obra fruto de mais de 20 anos de amadurecimento. Em El princípio pentecostalidad, o autor desenvolve em três momentos a sistematização deste princípio. Não só os pentecostais são frutos da pentecostalidade, que pode gerar expressões concretas e culturais (os pentecostalismos), mas atua nas igrejas, inclusive nas estruturas eclesiásticas:

Desde que cunhamos a palavra pentecostalidade a entendemos como critério epistemológico para falar da vocação de universalidade da igreja, e como categoria que permitiria superar as aporias da novidosa mas precária historização e institucionalização dos pentecostalismos, ao mesmo tempo que uma notae (características) da igreja. Cunhamos a categoria pentecostalidade porque necessitávamos uma categoria que, ao mesmo tempo que nos permitisse uma interpretação da eclesialidade (sectariedade?) dos pentecostalismos desde o ponto de vista endógeno, suscitasse também uma leitura objetiva, pública, inclusiva e verificável (CAMPOS, 2016, p. 130).

Na pentecostalidade estaria o princípio e a experiência universal fundante do Espírito, que pode fundar expressões concretas na força do 
Espírito. Pressupõe uma comunidade de fé e o evento crístico, salvador e transformador (CAMPOS, 2016).

Outro insight viria a partir da metáfora da profundidade de Paul Tillich (2009), quando explicava olugar da religião na sociedade moderna em Teologia e Cultura. Não seria uma área específica da vida nem teria um lugar concreto. O lugar da religião estaria na profundidade de todas as outras dimensões da vida. Ao buscar um lugar específico, estaria descaracterizando-a. Ao buscar situar-se na profundidade das demais dimensões da existência, encontraria seu lugar de modo transformador e fundante. De modo análogo, não basta escrever grandes tratados sobre pneumatologia hoje ou fazer disputar o Espírito na arena com outros temas teológicos, mas de descobrir na profundidade de todos os temas a dimensão pneumatológica. É preciso considerar seriamente outro princípio simultâneo, o Solus Spiritus Sanctus. Essa perspectiva espiritual poderia contribuir significativamente para uma igreja vivificada e na força do Espírito, para além de uma teologia formal ratificando que a reflexão e a sistematização são necessárias e importantes. Como afirma Junghans (2001, p. 18) a partir do pensamento de Lutero e citando o próprio Lutero: "A igreja precisa menos de livros do que de "pregadores bons, eruditos, espirituais e diligentes".

\section{Considerações finais}

Com a Reforma os pentecostais aprenderam que a pneumatologia deve ser cristológica e que a via do Espírito Santo não deve ser uma via alternativa ao Cristo, à Palavra, à fé e à graça. Com isso os pentecostais puderam desenvolver um quinto Sola, entendido de maneira integrada e simultânea com os quatro primeiros: o Solus Spiritus Sanctus. Nos pentecostais, não só a pneumatologia é cristológica, mas a cristologia é pneumatológica. Essa circularidade é também necessária para a teologia. Ou para usarmos a metáfora tillichiana da profundidade, a dimensão do Espírito Santo deveria ser resgatada em cada uma e em todas as dimensões da vida, da teologia e da igreja.

Fica um alerta para os excessos que a mística (seja a pentecostal ou outra) possibilita. Mas ao mesmo tempo, é preciso diferenciá-la, pois a mística também tem sua contribuição positiva. Por outro lado, é válido 
lembrar que a ortodoxia e a tradição tendem a se fechar e necessitam ser visitadas sempre e de novo pelo sopro do Espírito, que pode continuar nos surpreendendo. Redescobrir o Espírito, ou melhor, abrir-se para outras vias que não as que convencionamos, pode ser uma forma de reconhecer essa voz que nunca deixou de falar-nos, mas que nós sim deixamos de captá-la por nossas opções epistemológicas.

\section{Referências}

ALENCAR, G. F. Matriz pentecostal brasileira: Assembleias de Deus, 1911-2011. Rio de Janeiro: Novos Diálogos, 2013.

ALTMANN, W. Lutero e libertação. São Leopoldo: Sinodal; São Paulo: Ática, 1994.

CAMPOS, B. El principio pentecostalidad: la unidad en el Espíritu, fundamento de la paz. Oregon: Kerigma, 2016.

CAMPOS, B. Da reforma protestante à pentecostalidade da igreja: debate sobre o pentecostalismo na América Latina. São Leopoldo: Sinodal; Quito: CLAI, 2002 [1997].

CAMPOS, B. La madurez del hermano menor: los rostros del pentecostalismo latino-americano. Lima: Ieper, 2012.

DAYTON, D. Raíces teológicas del pentecostalismo. Buenos Aires: Grand Rapids, 1991.

DELUMEAU, J. La reforma. 3. ed. Barcelona: Labor, 1977.

FEE, G. D. Paulo, o Espírito e o povo de Deus. Campinas: United Press, 1997 [1994].

FRESTON, P. Protestantes e política no Brasil: da Constituinte ao impeachment. Tese de doutorado. Unicamp: Campinas, 1993.

FRESTON, P. Breve história do pentecostalismo brasileiro. In: ANTONIAZZI, A. et al. Nem anjos nem demônios. Interpretações sociológicas do Pentecostalismo. Petrópolis: Vozes, 1994.

GEE, D. Después de Pentecostés. Texas: Casa de Publicaciones [s.d.].

GEE, D. Como receber o batismo no Espírito Santo. Rio de Janeiro: CPAD, 2011. 
GEORGE, T. Teologia dos reformadores. São Paulo: Vida Nova, 1994.

GILBERTO, A. Pneumatologia: a doutrina do Espírito Santo. In: GILBERTO, Antonio (Ed.). Teologia sistemática pentecostal. Rio e Janeiro: CPAD, 2008. p. 171-244.

JUNGHANS, H. Temas da teologia de Lutero. São Leopoldo: Sinodal, 2001.

MARIANO, R. Neopentecostais, sociologia do novo pentecostalismo no Brasil. São Paulo: Loyola, 1999.

MENZIES, R. Pentecostes, essa história é a nossa história. Rio de Janeiro: CPAD, 2016.

MENZIES, W.; MENZIES, R. No poder do Espírito: fundamentos da experiência pentecostal. São Paulo: Vida, 2002.

MERTON, T. Novas sementes de contemplação. Montariol: Editorial Franciscana, 2007.

OLIVEIRA, D. M. de. Diálogo e missão nos Andes. Um estudo de teologia da missão latino-americana. São Paulo: Garimpo; Rio de Janeiro: Ed. PUC-Rio, 2016.

PALMA, A. D. O batismo no Espírito e com fogo: os fundamentos bíblicos e a atualidade da doutrina pentecostal. Rio de Janeiro: CPAD, 2014.

SANTIDRÍAN, P. R. Breve dicionário de pensadores cristãos. 2. ed. Aparecida: Santuário, 1997.

TILLICH, P. Teologia da cultura. São Paulo: Fonte Ediorial, 2009.

YONG, A. Discerning the Spirit(s): A Pentecostal-Charismatic Contribution to Christian Theology of Religions. Sheffield-England: Sheffield Academic Press, 2000.

Recebido: 02/05/2017

Received: 05/02/2017

Aprovado: 20/06/2017

Approved: 06/20/2017 
